\title{
Nutritional adequacy of menus offered to children of 2 - 5 years in registered childcare facilities in Inanda, KwaZulu-Natal Province, South Africa
}

\author{
P F Nzama, ${ }^{1}$ HDE, MAppSc; C E Napier, ${ }^{2}$ DTech, FSM \\ ${ }^{1}$ Department of Food and Nutrition, Durban University of Technology, South Africa \\ ${ }^{2}$ Department of Food and Nutrition, Institute of Systems Science, Durban University of Technology, South Africa
}

\author{
Corresponding author: P F Nzama (phindilen1@dut.ac.za)
}

\begin{abstract}
Background. The number of children that spend a large part of the day at childcare facilities (CCFs) has risen worldwide. The parent relies on caregivers in CCFs to provide children with balanced meals. Studies in various parts of South Africa (SA) that analysed CCF menus have found that the menus do not satisfy the daily requirements of energy and micronutrients for children. With increasing numbers of children attending CCFs, and an increase in the global prevalence of obesity, information with regards to food presented at the facilities was of interest not only to compare the energy, macro- and micronutrient intake, but also to consider the dietary diversity offered to the children on a daily basis.

Objectives. To analyse menus offered to children in CCFs in Inanda, KwaZulu-Natal for nutritional adequacy and to calculate the contribution the meals make to the dietary reference intakes for children in the 2 - 5-year age category.

Methods. Permission from the Department of Social Development (DSD) in Durban was obtained to approach the CCFs to participate in the study. Ten CCFs in the Inanda area were randomly selected from the DSD list of 45 registered CCFs. The researcher gathered menus, recipes and serving sizes from each of the 10 CCFs. Food Finder version 3 software (MRC, SA), adjusted to include fortified wheat and bread products, was used to analyse the recipes.

Results. The CCFs in Inanda served breakfast and lunch to the children daily. The top 20 list of foods offered cereal-based staples of rice and maize meal more frequently than meat, dairy products and fruit and vegetables. None of the CCFs met $60 \%$ of daily requirements for energy, fibre and calcium for children in this age group.

Conclusion. Menus offered to children aged 2 - 5 years in registered CCFs in Inanda are nutritionally inadequate.
\end{abstract}

S Afr J Child Health 2017;11(2):80-85. DOI:10.7196/SAJCH.2017.v11i2.1192

The South African Paediatric Food-Based Dietary Guidelines (SAPFBDG) state the necessity to provide sufficient nutrients in meals to support optimal growth and development in children. ${ }^{[1]}$ Childhood is an intermediary nutritional passage from dependence on a caregiver regarding food choices, to children making individual food choices. Furthermore, at this stage children establish eating habits and individual feeding behaviour that will eventually have an impact on society, as the development of diet-related diseases in adulthood is prevented by establishing healthy eating habits from childhood. ${ }^{[1,2]}$ Therefore, meals served at childcare facilities (CCFs) to children from 6 months to 6 years should have dietary variation and ideally contain ingredients from all the major food groups.

The minister of social development stated that Early Childhood Development (ECD) programmes are mainly a strategy for alleviating poverty. The programmes should be planned to deal with the total well-being of children by making certain that children grow up, among other things, healthy and well-nourished. ${ }^{[3]}$ In 2009, the Department of Social Development (DSD) reported that in South Africa (SA), the ECD sites as well as children's enrolment in those sites had increased to 646491 children aged $\leq 4$ years in 13736 registered ECD sites, and 620223 5-year-olds registered for grade R in schools and ECD sites that are run by non-profit organisations. The government's subsidy for ECD programmes ranged from ZAR9 to ZAR12 allocated per child to be used towards the full stay of the child including food, stationery and salaries and is one of the strategies for poverty eradication. The subsidy is intended to fund day-care site employees and overheads as well as nutrition. ${ }^{[4]}$ Biersteker and Dawes ${ }^{[5]}$ concurred that high-quality ECD service provision for poor children was a justified cost, as it not only improves the child's well-being, but also prevents problems related to childhood poverty in later stages of life.
In SA, the Child Care Act of 1983, Regulation 38, provides the conditions for ECD facilities for children's meals. The regulation states that the place of care shall operate for a minimum of 8 hours a day, and meals and refreshments shall be served to the child who is present at meal times or tea times. ${ }^{[6]}$ The Children's Act of 2005 and regulations thereof enable and regulate the provision of ECD services to young children and the DSD created the Guidelines for Early Childhood Development Services (GECDS) to provide direction on how to support the nutritional needs of young children in ECD programmes.

According to Neelon and Briley, ${ }^{[7]}$ CCFs that operate for $4-7$ hours should provide $33.3 \%$ of the everyday nutritional needs of preschool children. Furthermore, a CCF that operates for 8 or more hours should provide at least $50 \%$ to $66.6 \%$ of a child's daily nutritional requirements. Food should also be served in the correct quantities to balance the energy and nutrient requirements of children of different ages. ${ }^{[7]}$

The deficiency of macro- and micronutrients such as protein, carbohydrates, energy, dietary fibre, calcium, iron, zinc and vitamin A in the diet of children result in stunted growth, wasting, underweight and poor brain development. These deficiencies can also result in a low resistance to infections. Low immunity may cause specific diseases and increase the severity of infectious diseases and chronic illnesses, which ultimately has an influence on the child's well-being and poses a risk of mortality. ${ }^{[8,9-12]}$

According to Briley and Roberts-Gray, ${ }^{[13]}$ offering children a variety of foods at each meal improves nutrient intake and encourages the establishment of good eating habits, personal preferences, and continued contributions to growth and development. The age of the children and the stage of mental development should be considered when planning meals. In children, eating habits contribute to meeting nutritional requirements, nutritional adequacy, and the promotion of growth. ${ }^{[13]}$ As 
CCFs determine the child's daily routine, including meal plans, these facilities are platforms for the improvement of the child's nutritional and physical status. ${ }^{[14]}$

\section{Methods \\ Study design and setting}

The study was descriptive, cross-sectional, and observational, and included interviews, observations and plate waste studies, which were carried out at all participating CCFs. According to the DSD, 45 CCFs were registered in Inanda at the time of the study. Each CCF served an average of 80 children per meal time.

Inanda has nearly half a million residents in what is one of the largest conglomerations of informal settlements in SA. It is situated $20 \mathrm{~km}$ from the central business district of Durban and is described as a low-income residential area with a high number of poorly educated and unemployed youth. ${ }^{[15]}$

\section{Ethical considerations}

The study was approved by the Faculty Research Committee at the Durban University of Technology (DUT) and adhered to the SA Medical Research Council (SAMRC)'s research ethics guidelines. An ethics registration number was not issued as the children were not included in the study and therefore it was classified as low-risk. The request to conduct the study was acknowledged in writing by the regional director of the DSD. Written consent was obtained from each of the 10 managers at the randomly selected facilities. Anonymity of the data was ensured by allocating a number to each of the CCFs.

\section{Sampling}

The study respondents were CCFs accommodating children aged 3 - 5 years. The first contact was made through communication with the DSD to obtain permission to conduct the study among registered CCFs. The DSD provided a list of registered CCFs to the researcher; thereafter, 10 CCFs were randomly selected and approached to participate in the study. On the first visit to a CCF, the researcher met with the owner and/or supervisor to explain the requirements of the study and to obtain signed consent for participation.

\section{Data collection methods and analysis}

The researcher spent 5 days of the week in each facility to collect the facility's menu plans and recipes, and to conduct plate-waste studies for the meals that the CCFs offered. No standardised recipes were available at any of the facilities. Ingredients were weighed uncooked and peeled. The mass and volume of ingredients were recorded on a list of ingredients and the method was written on a recipe sheet from observation and questioning of the food handler (FH). The researcher used a menu sheet to record daily menu plans for each CCF, on 5 days of the week, while the FH was preparing meals. Plate waste studies incorporated a weighed method for accurate measurement of nutrient intake and portion sizes. ${ }^{[16]}$

All meals served to the children in the sample group ( $n=20$ per CCF) were weighed on a Digi DS-708 electronic kitchen scale prior to serving. Plates were weighed again after meal consumption and plate waste was documented. Actual food intake was recorded after deducting plate waste from the served portion sizes. The mean intake and average portion size consumed per age group was subsequently calculated and used for nutrient analysis. These measurements were conducted at breakfast and lunch times, 5 days a week in each CCF.

All breakfast and lunch menus, average portion sizes and recipes from the weighed food records were captured using Excel 2007. The data were analysed using Food Finder version 3 software (MRC, South Africa), ${ }^{[17]}$ which was updated to include fortified bread and wheat product recipes, to obtain the top 20 foods served at the $10 \mathrm{CCF}$. The software was also used to determine the nutrient contribution of the menus to the nutritional requirements of the children. The nutrient contribution of the CCF menus was compared to $60 \%$ of the dietary reference intakes (DRIs) for children 3 - 5 years of age using the DRIs from the Institute of Medicine, ${ }^{[18]}$ as $50-66 \%$ nutrient compliance is recommended for CCFs operating 8 or more hours a day. ${ }^{[7]}$

\section{Results \\ Nutrient analysis}

The tables present the energy contribution of macronutrients, protein, carbohydrates and fibre, as well as the micronutrients calcium, iron, zinc and vitamin A, as adequacy of these nutrients is essential in childhood.

Table 1 presents the menu contribution to the daily nutrient intake of boys and girls aged 2 - 3 years old. Meals at CCFs 1, 2, 5, 7, and 10 met the requirements for protein and carbohydrates, while CCF 9 met the requirements for carbohydrates. All the CCFs failed to meet the energy needs of the children, except CCF 2 where the energy requirement for girls was adequate although boys were slightly below the DRI at 59.3\%.

At all CCFs the mean dietary fibre provided by both meals was below $30 \%$ of the World Health Organization (WHO)'s recommendation of $>25 \mathrm{~g} /$ day or $>15 \mathrm{~g}(60 \%)$ for $2-3$ year olds. None of the CCF meals met the requirements for calcium. The only meals exceeding $60 \%$ of the DRIs for vitamin A $(210 \mu \mathrm{g})$ were found in CCFs 2 and 7, which contributed $>100 \%$ of the DRIs. The results also show that for this age category, only 5 CCFs met the requirements for zinc and 5 met the requirements for iron.

Table 2 indicates the results of the nutrient analysis for all CCFs for the 4 - 5-year-old children. None of the five CCFs met the requirements for a $60 \%$ contribution to energy intake, dietary fibre and calcium. Only CCFs 4 $(49.2(45.2) \mathrm{g})$ and 8 at $57.6 \mathrm{~g}(15.6)$ were below the $60 \%$ requirements for carbohydrates. More than $60 \%$ of DRIs for protein were met by meals at CCFs 1 (16.2 (4.8) g), 2 (19.1 (1.7) g), 5 (12.2 (6.3) g) and 7 (14.6 (4.8) g). CCFs 1,2 and 7 also met the requirements for zinc and vitamin $A$, and the meals in CCFs 3 and 7 provided $>60 \%$ of the DRIs for iron.

\section{Top 20 food intake}

All participating CCFs opened at $07 \mathrm{~h} 00$ and closed at $15 \mathrm{~h} 00$ or $16 \mathrm{~h} 00$. The 5-day menu plans recorded onsite were used to identify the top 20 food items served by the CCFs. CCF 10 did not provide meals for 2-yearolds. Table 3 illustrates the top 20 foods that were served at the CCFs collectively for the 5 days of the week, ranked by total intake of all CCFs. The top 20 list is presented for each age group, as each age group has different nutritional needs.

Maize meal and rice were offered almost daily as part of the breakfast and lunch menu at all the CCFs. Maize meal was offered in the form of porridge, crumbly phuthu and stiff pap. The CCFs served maize meal porridge with milk, sugar, peanut butter, margarine and Morvite. CCFs 4, 7 and 10 served Morvite on Fridays. Maltabella, a breakfast cereal made from sorgum grains, was served by CCFs 8 and 10 once a week and biweekly at CCF 1 . Two CCFs served cornflakes for breakfast once during a 5-day period.

All CCFs (except CCF 10) served rice to 2-year-olds, as rice is considered soft and palatable for younger children. Rice was also the starch of choice for the older age groups at lunch. At teatime, CCF 6 served sliced brown or white bread with tea to 5-year-olds. On Fridays, CCF 4 served Morvite and polony sandwiches made from brown bread, with diluted, sweetened juice because there was no electricity to cook meals. Other sources of carbohydrates for the younger children included dhal soup, dhal and bean soup, baked bean soup, and samp and beans with fish soup. Soup powders were used to thicken soups and curries in all CCFs.

Milk was only offered at breakfast time, with porridge, in some CCFs. In one CCF, $375 \mathrm{~g}$ Nespray powdered milk was added to a $25 \mathrm{~L}$ pot of porridge. Milk was also served with cornflakes for breakfast at two CCFs. Milk quantities were stretched by adding $500 \mathrm{~mL}$ of water to $1 \mathrm{~L}$ of milk. Some CCFs also served maas and phuthu once a week.

Canned fish was widely offered as fish soup ranked number three on the top 20 list for both age groups. The fish bones were removed from the fish before preparing the soup. For the 2- to 3-year-olds, as illustrated 
in Table 3, canned fish soup was served with rice in the CCFs. Canned fish was also cooked with dhal and served with rice. Canned fish soup with samp and beans was served in two CCFs. Other sources of protein included minced meat soup, chicken and dhal soup and chicken curry served once in the 5 days at different CCFs.

The fruit and vegetable intake of the children was far below the recommended intake of the WHO of $>400 \mathrm{~g}$, and $>240 \mathrm{~g}(60 \%)$ for a CCF, respectively. Only CCF 2 presented the children with a piece of fruit on four days of the week, at tea time. Generally, each child would receive either half an apple or orange $(45(0) \mathrm{g})$. Commonly used fresh vegetables included onions, potatoes, green beans, green peppers, tomatoes, spinach and carrots, and frozen vegetables included carrots, green beans and sweetcorn and were used mainly in soups and curries.

\section{Discussion}

Menus served in all Inanda CCFs did not provide $>60 \%$ of the DRIs for energy, dietary fibre and calcium. Various studies have concluded that CCF meals usually do not meet the requirements for energy and micronutrients in children. ${ }^{[19-21]}$ Results of studies conducted in 40 New York- and 20 Texasbased childcare centres showed that meals were below the RDAs for micronutrients and energy. ${ }^{[21,22]}$

The use of fats, salt and sugar in meals in the Inanda CCFs was in line with the SAPFBDGs, as these condiments were used sparingly during food preparation, as seen in the top 20 foods list in Table 3. On the other hand, this resulted in menus not meeting the energy needs of the children. In childhood, energy is needed for increased activity and growth. ${ }^{[18,23]}$ In developing countries, factors such as the burden of infectious diseases such as diarrhoea and parasitic infections, micronutrient deficiencies and catch-up growth increases the need for energy in children. ${ }^{[24}$

The meals served at the CCFs in Inanda $(n=10)$ were nearly identical, with very little variation in the food items employed in menu construction. The mean portion served for starch items, as seen in Table 3 , is above the recommended 40 and $60 \mathrm{~g}$ for children aged $1-3$ and $4-6$ years old, respectively. For children aged 1 - 3 years, the portion sizes for meat and vegetable dishes should be $70-80 \mathrm{~g}$, of which $40-50 \mathrm{~g}$ is the recommended portion size for protein; $30 \mathrm{~g}$ is recommended for the vegetable portion, excluding soup. Children aged 4 - 5 years should be served at least $110 \mathrm{~g}$ of mixed meat and vegetable dishes, as $60 \mathrm{~g}$ is recommended for protein and $50 \mathrm{~g}$ is recommended for vegetables, excluding soup. ${ }^{[25]}$

There was a lack of dietary fibre in meals at the CCFs, because of low consumption of fibre-rich carbohydrate foods such as whole grain cereals, fruits, and vegetables. Children were served refined cereals daily, and beans, dhal and samp once or twice weekly. This is in line with the SA Food Guide and the SAPFBDGs, which illustrates that starch should be consumed with most meals. The SAPFBDGs also state that legumes should be eaten regularly and that the food items consumed should be of good quality, in correct amounts and

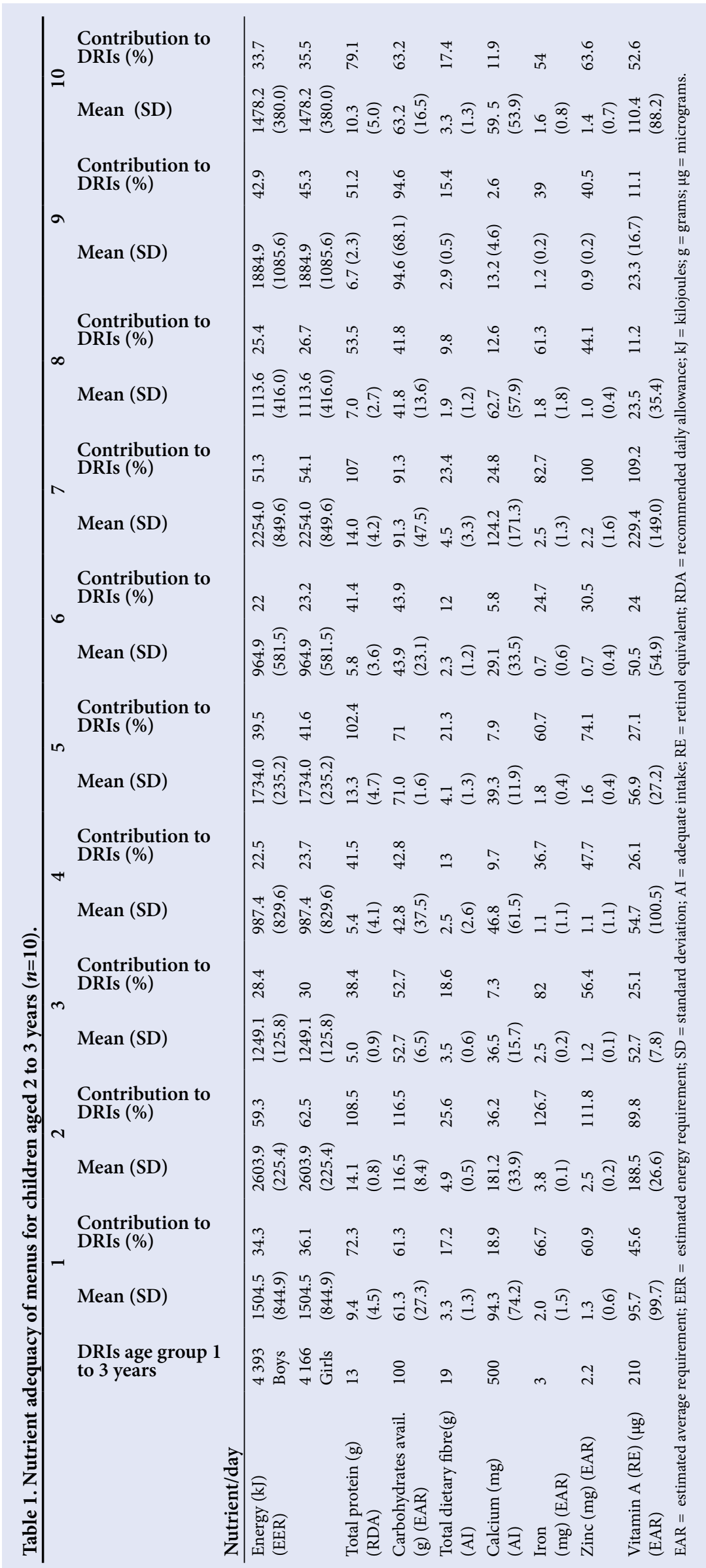




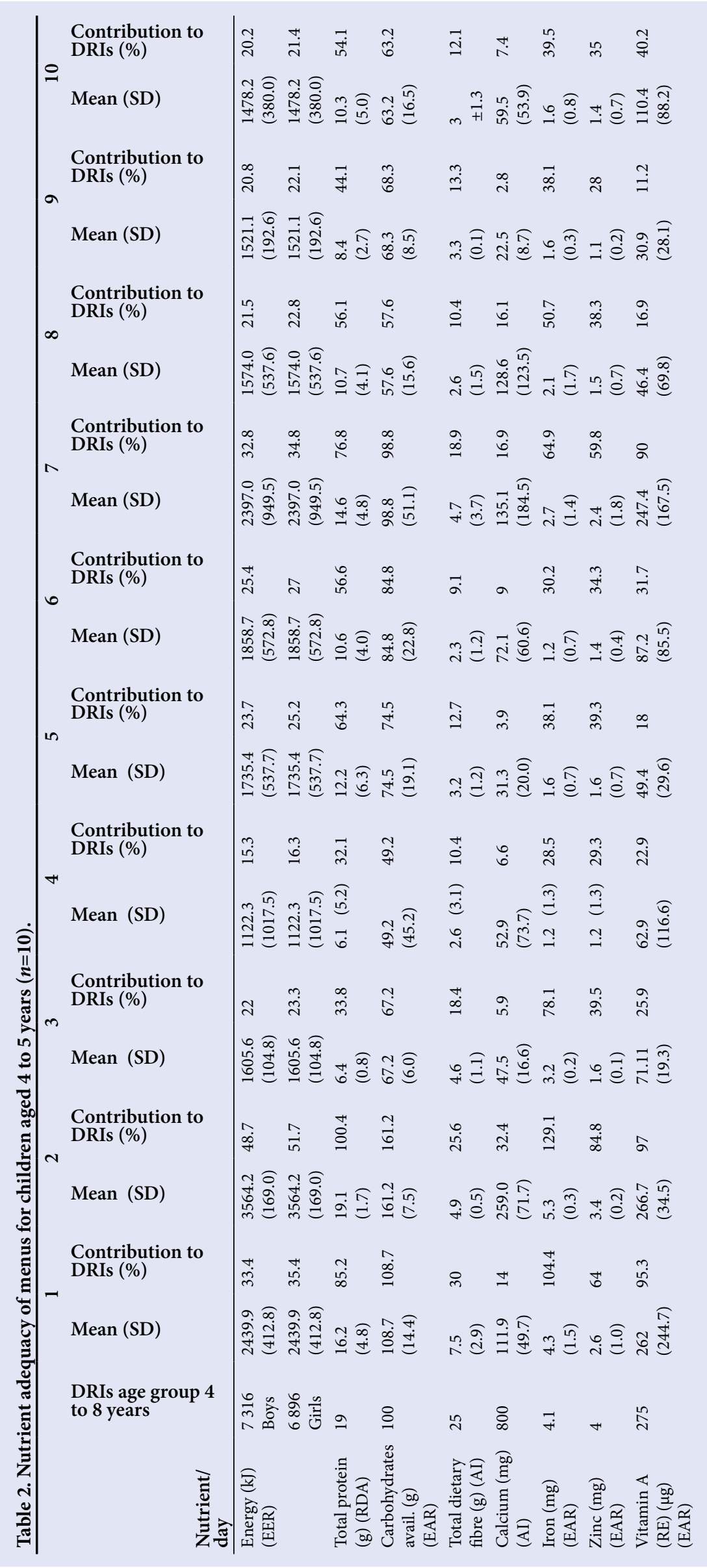

according to the child's needs to contribute to the total daily intake, which is lacking in the CCFs meals. ${ }^{[26]}$

Inadequate quantities of fruits and vegetables were offered, as none of the CCFs met $60 \%$ (240 g) of the WHO's $400 \mathrm{~g}$ minimum recommended consumption for the day. The SAPFBDGs state that children should be given fruits and vegetables every day. ${ }^{[27]}$ Vitamins and mineral substances obtained from consuming fruit and vegetables are essential to boost immunity and fight infections and illnesses in the body ${ }^{[28]}$ A study in Mangaung, Free State Province, SA, found that a cereal-based diet and low intake of fruit and vegetables resulted in low vitamin $\mathrm{C}$ and bioavailable iron. ${ }^{[20]}$ Furthermore, the results of a study in the Limpopo Province of SA found that the meals served at CCFs in the province were mainly cereal-based with maize meal porridge. ${ }^{[29]}$ There was a low intake of fruit and vegetables, which contributed to a low vitamin A intake. But a study conducted in rural villages in KwaZuluNatal showed that increasing the intake of dark green leafy vegetables, especially the indigenous types, contributed considerably to the total intake of calcium, vitamin A and riboflavin. ${ }^{[30]}$

Children should also be served about 600 $700 \mathrm{~mL}$ of milk per day to meet daily requirements. ${ }^{[25]}$ The GECDS recommends that children should be given skimmed milk to drink. ${ }^{[6]} \mathrm{CCF}$ in Inanda do not serve adequate amounts of calcium-rich foods (Table 3). The inadequacy of calcium-rich foods in the menus is contrary to the SAPFBDGs, which recommend that children of 24 months to 5 years should be given milk, maas or yoghurt every day. ${ }^{[27]}$ At this age, calcium is needed as a blood clotting factor, to heal wounds, in the formation of bones and teeth, muscle contraction and nerve transmission. ${ }^{[31]}$

A similar study in Free State Province in $\mathrm{SA}^{[20]}$ found that protein was sufficient but the meals were low in iron, zinc, calcium and vitamin A, which suggested that the protein sources were of low quality. In this study, protein consumption was inadequate because high quality protein foods were served in small quantities and only once or twice weekly. The CCFs fell short of SAPFBDGs, which state that children younger than 5 years could eat lean chicken or lean meat or fish or eggs every day or as often as possible. In a study in Cape Town ${ }^{[19]}$ protein exceeded recommended DRIs as CCFs were serving high-quality protein foods such as meat, eggs, fish, cheese and chicken. However, in the same study, meals were low in thiamine, riboflavin, zinc, vitamin D, folate and vitamin E, and DRIs for energy, calcium and iron were never met. Some meals also did not provide vitamins $\mathrm{A}, \mathrm{B}_{12}, \mathrm{C}$ and $\mathrm{D}$ at all. ${ }^{[19]}$ Animal protein sources are needed to build and maintain body tissues and red meat is a good source of iron, which assists in the production of red blood cells. ${ }^{[28]}$

Worldwide, there is a problem with CCF feeding, which needs to be addressed and improved. The results of this study show that the Inanda CCFs were not very different from the rest of the world when it came to the nutrient adequacy of menus served to children. 
For this reason the American Dietetic Association created guidelines for childcare nutrition for 2 - 5- year-old children, which stipulate that CCFs should serve fresh, raw or frozen fruit and vegetables rich in vitamin C every day. Vitamin A-rich foods should be served on 3 days of the week, as should wholewheat grain products like bread and oats, which are a good source of dietary fibre. Children should also drink fat-free milk for their vitamin $\mathrm{D}$ and calcium requirements. ${ }^{[7]}$ The meals in the Inanda CCFs need to keep in line with the GECDS as well as SA Food Guide and the SAPFBDGs. Training of food handlers and owners of the CCFs could lead to improved menus and optimal use of available funding in making nutrient-dense menu choices.

\section{Conclusion}

This study has found that menus served to 2 - 5-year-olds in registered CCFs in Inanda were nutritionally inadequate as most CCFs did not meet the $60 \%$ daily requirements for many nutrients from menus served in the CCFs. It is almost impossible to provide $60 \%$ of the daily requirements for children on the ZAR9 to ZAR12 allowance presented by the government, making it important for government to consider funding CCFs to contribute to poverty alleviation in resourcepoor communities. A follow-up study could assist in developing menus that are nutritionally adequate yet affordable in this context. The sensory evaluation of food on offer should be conducted with the children to ensure that the menu items on offer are culture- and ageappropriate.

Acknowledgements. We thank the owners, teachers, parents and children in the registered CCFs in Inanda for granting us permission and warmly welcoming us and working harmoniously with us in this study. This was all much appreciated.

Author contributions. PFN collected and analysed the data, and wrote the manuscript. CEN supervised the research and reviewed the manuscript.

Funding. Durban University of Technology.

Conflict of interest. None.

1. Bowley NA, Pentz-Kluyts MA, Bourne LT, et al. Feeding the 1 - 7-year-old child. A support paper for the South African paediatric foodbased dietary guidelines. Matern Child Nutr 2007;3(4):281-291. https://doi.org/10.1111/ j.1740-8709.2007.00112.x

2. Schwartz C, Scholten JPAM, Lalanne A, Weenen $\mathrm{H}$, Nicklaus S. Development of healthy eating habits early in life. Review of recent evidence and selected guidelines. Appetite 2011;57(3):796-807.

3. Department of Social Development. 2nd Technical workshop of the Africa Early Childhood Care and Development Initiative. 2010. www.dsd.gov. za (accessed 20 March 2014).

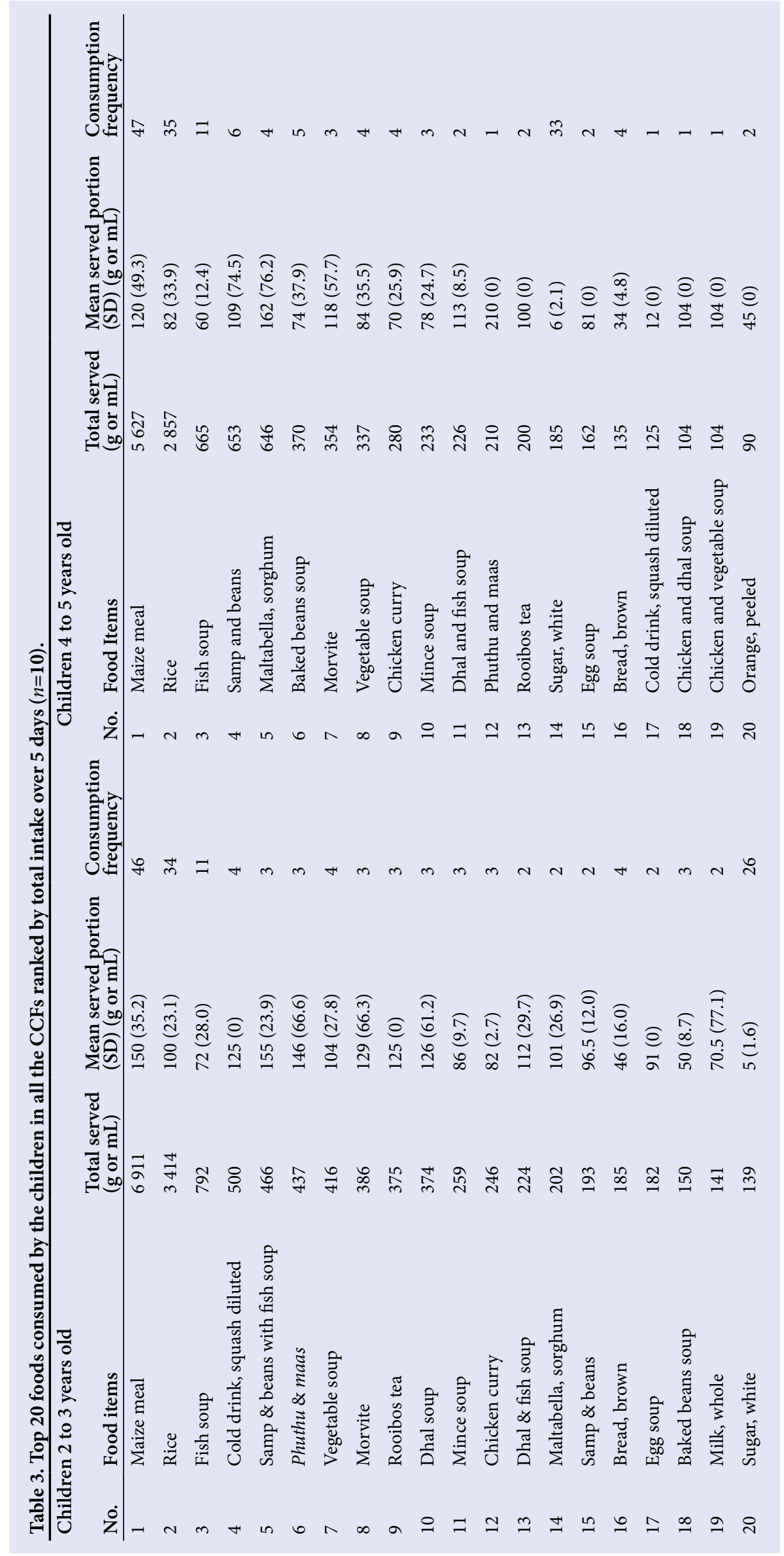


4. Department of Basic Education. Education for All South Africa Country Report 2009. 2010. http://www.gov.za/sites/www.gov.za/files/DoBE_EFA\%20 Country\%20Report\%202009_07062010.pdf (accessed 29 August 2016).

5. Biersteker L, Dawes A. Early childhood development. In: Kraak A, Press K, eds. Human resources development review: Education, employment and skills in South Africa. Cape Town: HSRC Press, 2008:185-205.

6. Department of Social Development Republic of South Africa. Guidelines for Early Childhood Development Services. 2008. www.unicef.org/southafrica/ SAFresources_ecdguidelines.pdf (accessed 24 January 2012).

7. Neelon BSE, Briley ME. Position of the American Dietetic Association: Benchmarks for nutrition in child care. J Am Diet Assoc 2011;111(4):607-615. https://doi.org/10.1016/j.jada.2011.02.016

8. Petrou S, Kupek E. Poverty and childhood undernutrition in developing countries: A multi-national cohort study. Soc Sci Med 2010;71(7):1366-1373. https://doi.org/10.1016/j.socscimed.2010.06.038

9. Black MM. Micronutrient deficiencies and cognitive functioning. J Nutr 2003;133(11):3927S-3931S.

10. Buhl A. Meeting Nutritional Needs Through School Feeding: A Snapshot of Four African Nations. Global Child Nutrition Foundation. 2010.

11. Tulchinsky TH. Micronutrient deficiency conditions: Global health issues. Pub Health Rev 2010;32(1):243-255. https://doi.org/10.1007/bf03391600

12. Nordin SM, Boyle M, Kemmer TM. Position of the Academy of Nutrition and Dietetics: Nutrition security in developing nations: Sustainable food, water, and health. J Acad Nutr Diet 2013;113(4):581-595. https://doi.org/10.1016/j. jand.2013.01.025

13. Briley ME, Roberts-Gray C. Position of the American Dietetic Association: Nutrition standards for childcare programs. J Am Diet Assoc 1999;99(8):981988. http://dx.doi.org/10.1016/S0002-8223(99)00235-7

14. Vossenaar M, Panday B, Hamelinck V, et al. Nutrient offerings from the meals and snacks served in four daycare centers in Guatemala City. Nutrition 2011;27(5):543-556. https://doi.org/10.1016/j.nut.2010.06.007

15. Everatt D, Smith M. Building sustainable livelihoods: Analysing a baseline (2006) and measurement (2008) survey in the 22 nodes of the Urban Renewal Programme and Integrated Sustainable Rural Development Programme. Pretoria: Department of Social Development, 2008.

16. Carr D, Levins J, Lindeman A. Plate waste studies. Practical Research. USA: National Food Service Management Institute, 2000.

17. Wolmarans P, Kunneke E, Laubscher R. The use of the South African Food Composition Database System (SAFOODS) and its products in assessing dietary intake data. Part II. S Afr J Clin Nutr 2009;22(2):59-67. https://doi.org/ 10.1080/16070658.2009.11734220
18. Dietary reference intakes: Applications in dietary planning. National Academies Press, 2003. https://doi.org/10.17226/10609

19. Pietersen C, Charlton K, du Toit M, et al. An assessment of the nutrient conten of meals provided and facilities present at state-funded crèches in Cape Town. S Afr J Clin Nutr 2007;15:15-24.

20. Dannhauser A, Bester C, Joubert G, et al. Nutritional status of preschool children in informal settlement areas near Bloemfontein, South Africa. Public Health Nutr 2000;3(3):303-312. https://doi.org/10.1017/s1368980000000343

21. Erinosho T, Dixon LB, Young C, et al. Nutrition practices and children's dietary intakes at 40 child-care centers in New York City. J Am Diet Assoc 2011;111(9):1391-1397. https://doi.org/10.1016/j.jada.2011.06.001

22. Padget A, Briley ME. Dietary intakes at child-care centres in central Texas fail to meet Food Guide Pyramid recommendations. J Am Diet Assoc 2005;105(5):790-793. http://dx.doi.org/10.1016/j.jada.2005.02.002

23. Food and Agriculture Organisation (FAO). Report of a joint FAO, WHO, UNU expert consultation. Human Energy Requirements. 2001. http://www.fao.org/ publications/card/en/c/elfaed04-3a4c-558d-8ec4-76ala7323dcc/ (accessed 9 September 2013).

24. Swart R, Dhansay A. Nutrition in Infants and preschool children. In: Community Nutrition Textbook for South Africa: A Rights-based Approach. Chronic Diseases of Lifestyle Unit: Medical Research Council, 2008:377-440.

25. Gordon-Davis L, van Rensburg L. The Hospitality Industry Handbook on Nutrition and Menu Planning. Cape Town: Juta \& Co., 2004:138-144.

26. Department of Health. Guidelines for Healthy Eating for Nutrition Educators. Pretoria: DOH, 2012.

27. Vorster HH, Badham J, Venter C. An introduction to the revised food-based dietary guidelines for South Africa. S Afr J Clin Nutr 2013:26:S5-S12.

28. Faber M, Laurie S, Ball A, et al. A Crop-based Approach to Address Vitamin A Deficiency in South Africa. Medical Research Council - Cape Town/ ARCRoodeplaat, Pretoria: DOH, 2013:35-60.

29. Kwinda PC, van der Spuy E, Viljoen AT. Application of a food-based dietary guidelines as nutrition strategy in crèches to enhance vitamin A consumption. J Fam Ecol Consumer Sci 2011;39:56-67.

30. Faber M, van Jaarsveld PJ, Laubscher R. The contribution of dark-green leafy vegetables to total micronutrient intake of two- to five-year-old children in a rural setting. Water SA 2009;3(3):407-412. https://doi.org/10.4314/wsa. v33i3.49153

31. Stein AJ. Global impacts of human mineral malnutrition. Plant Soil 2010;335(1):133-154. https://doi.org/10.1007/s11104-009-0228-2 